\title{
Prosedur Pemeliharaan Barang Jaminan Dalam Perspektif Ekomomi Syariah Di Pegadaian Cabang Subang
}

\author{
Ida Rosdiana ${ }^{1}$, Rina Nurhayati ${ }^{2}$, M.Cahyo Sucipto ${ }^{3}$ \\ ${ }^{1}$ STAI Riyadhul Jannah Subang \\ ${ }^{2}$ Universitas Padjadjaran \\ ${ }^{3}$ STIES Indonesia Purwakarta \\ Jln. Veteran no 150-152 Purwakarta 41118 Jawa Barat Indonesia \\ 1idarosdiana@gmail.com \\ 2inamaza212@gmail.com \\ 3cahyosucipto@gmail.com
}

\begin{abstract}
Abstrak - Artikel ini membahas tentang pemeliharaan barang jaminan yang merupakan biaya yang dibebankan kepada rahin/nasabah untuk menjaga dan merawat barang jaminan agar tidak hilang dan pada saat dikembalikan sama seperti yang diterima. Jumlah dari biaya yang dibebankan tersebut ditentukan berdasarkan nilai taksiran barang jaminan dan dalam jangka waktu yang ditentukan pada saat akad. Tujuan dari penelitian ini adalah untuk mengetahui aturan pelaksanaan pemeliharaan barang jamian dan untuk mengetahui pelaksanaan pemeliharaan barang jaminan di Pegadaian Cabang Subang. Dan tinjauan ekonomi syariah tentang pelaksanaan pemeliharaan barang jaminan. Metode penelitian yang digunakan adalah metode deskriptif kualitatif yaitu penelitian yang menggambarkan serta menyajikan suatu peristiwa yang terjadi di lapangan dengan menggunakan teknik pengumpulan tringulasi data yaitu melalui observasi, wawancara, dokumentasi, dan juga penelitian kepustakaan dengan membaca buku, jurnal, artikel, website yang berkaitan dengan masalah yang akan diteliti. Hasil penelitian menunjukan bahwa pelaksanaan pemeliharaan barang jaminan di Pegadaian Cabang Subang sudah sesuai dengan fatwa maupun peraturan pemerintah. Dalam fatwa maupun peraturan pemerintah pelaksanaan pemeliharaan barang jaminan diperbolehkan. Barang jaminan sama halnya dengan amanat. Pegadaian akan memberikan ganti rugi jika barang jaminan milik nasabah rusak. Maka dari itu Pegadaian akan berusaha semaksimal mungkin agar barang jaminan milik nasabah tidak rusak. Dalam menunjang kegiatan tersebut Pegadaian mengenakan biaya penyimpanan dan pemeliharaan. Dengan begitu hadirnya Pegadaian diharapkan mampu menekan munculnya peminjaman yang cenderung merugikan masyarakat yang sedang membutuhkan. Akan tetapi penulis tidak menemukan aturan yang menjelaskan mengenai nilai maksimal biaya pemeliharaan barang jaminan atau berapa besar biaya pemeliharaan barang jaminan yang seharusnya ditanggung oleh rahin. Pemeliharaan barang jaminan dibebankan kepada nasabah yaitu tergantung dari kebijakan atau peraturan masingmasing perusahaan.
\end{abstract}

Kata Kunci : Gadai, Pemeliharaan Barang Jaminan, Fatwa Dewan Syariah Nasional, Pegadaian.

\begin{abstract}
This article discusses the maintenance of collateral items wich are fees charged to the rahin / customer to maintain and maintain collateral to prevent it from being lost and when it is returned the same as received. The amount of the fee charged is determined based on the estimated value of the collateral and within the period specified at the time of the contract. The purpose of this study was to determine the rules of maintenance of collateral and to find out the implementation of maintenance of collateral in the pawnshop Subang Branch. And a review of sharia economics regarding the maintenance of collateral. The research method used is descriptive qualitative method that is the research presented and presents research carried out in the filed using tringulation data collection techniques through observation, interviews, documentation, and also library research by reading books, journals, articles, websites related to the problem to be studied. The results showed that the implementation of maintenance of collateral items in the Subang Branch Pawnshop was in accordance with fatwas and government regulations. In fatwas and government regulations the implementation of
\end{abstract}




\section{EKSISBANK Vol. 4 No. 1 Juni 2020}

maintenance of collateral is permitted. Collateral is the same as the mandate. Pegadaian will provide compensation if the collateral belonging to the customer is damaged. Therefore Pegadaian will make every effort so that the customer's collateral items are not damaged. In supporting these activities Pegadaian charges storage and maintenance fees. Thus, the presence of Pegadaian is expected to be able to reduce the emergence of loans that tend to disadvantage people who are in need. However, the author did not find a rule that explains the maximum value of maintenance costs for collateral or how much maintenance costs of collateral should be borne by the womb. Maintenance of collateral is charged to the customer, which depends on the policies or regulations of each company.

Keywords : Pawn, Maintenance of Collateral, National Sharia Council Fatwa, Pegadaian.

\section{PENDAHULUAN}

Pemeliharaan barang jaminan merupakan hubungan antara dua akad yaitu akad rahn dan akad Ijarah. Timbulnya akad ijarah dikarenakan adanya transaksi gadai yang dilakukan sebelumnya. Yaitu memberikan pinjaman kepada masyarakat dengan jaminan benda berdasarkan hukum gadai. Maka timbul biaya perawatan dan sewa tempat dalam sistem gadai yang disebut dengan ijarah. Yaitu pemindahan hak guna atas barang tanpa diikuti dengan kepemilikannya. Kemungkinan akad ini yaitu untuk menarik sewa atas penyimpanan barang (Ichsan, 2016; Maemunah, 1970). Dengan demikian nasabah akan memberikan biaya jasa simpan karena telah menitipkan barangnya agar dijaga dan dirawat (Janwari, 2015).

Pengertian gadai atau Rahn secara bahasa berarti tsubut wa dawam (tetap dan lama). Ada sebagian yang mengatakan bahwa, makna Rahn tertahan, dengan dasar firman Allah SWT dalam QS. Al-Muddatsir ayat 38.

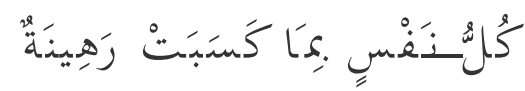

"Tiap-tiap diri bertanggung jawab (tertahan) atas apa yang telah diperbuatnya".

Kata rahinah dalam ayat tersebut bermakna tertahan. Pengertian kedua ini hampir sama dengan yang pertama karena yang tertahan itu berada tetap di tempatnya (Hafidah, 2013; Haikal, 2018). Gadai atau Rahn menurut syari'ah adalah penyerahan harta benda sebagai jaminan hutang, yang hak kepemilikannya dapat diambil alih ketika sulit untuk menebusnya (Janwari, 2015).

Melalui penggunaan akad ijarah ini nasabah akan memberikan jasa simpan kepada murtahin untuk pemeliharaan barang. Pegadaian menjadi media yang difungsikan sebagai pengaman atau sebagai jasa titip barang.

Untuk biaya pemeliharaan barang jaminan dalam fatwa Dewan Syari'ah Nasional (DSN) No.25/DSN-MUI/III/2002 bagian ke-4 menyebutkan bahwa besar biaya pemeliharaan dan penyimpanan marhun tidak boleh ditentukan berdasarkan jumlah pinjaman. Sedangkan jumlah pinjaman itu sendiri tergantung pada nilai jaminan yang diberikan. Semakin besar nilai barang maka semakin besar jumlah pinjaman yang diperoleh oleh nasabah atau rahin.

Di Kantor Pegadaian Cabang Subang pada prakteknya berdasarkan wawancara dengan bapak Yudha Ramdhani pada hari jumat, 29 Maret 2019 mengenai transaksi gadai adalah menahan salah satu harta milik peminjam sebagai jaminan atas pinjaman yang diterimanya. Barang yang ditahan tersebut memiliki nilai ekonomis, dengan demikian pihak yang menahan memperoleh jaminan untuk dapat mengambil seluruh atau sebagian piutangnya.

Akad rahn tersebut terdapat biaya pemeliharaan dan penyimpanan, yakni biaya yang dibutuhkan untuk menjaga dan merawat marhun selama jangka waktu yang ditentukan pada akad rahn. Pelaksanaan pemeliharaan barang jaminan di Kantor Pegadaian Cabang Subang tersebut yaitu adanya pemungutan biaya yang besar pinjaman dan biaya pemeliharaannya ditetapkan berdasarkan jenis barang yang akan digadaikan atau penaksiran harga barang yang akan digadaikan. Murtahin atau penerima barang melihat terlebih dahulu jenis barang seperti apa yang akan dijadikan sebagai jaminan lalu ditentukan jumlah pinjaman yang akan diberikan(Bukido \& Hasan, 2016).

Gadai syari'ah merupakan produk dengan menggunakan sistem penyaluran pinjaman secara gadai yang didasarkan pada penerapan sistem syari'at Islam. Nasabah tidak dikenakan bunga pinjaman atas pinjaman yang diberikan. Nasabah dikenakan biaya jasa simpan dengan alasan agunan yang diserahkan nasabah wajib disimpan, diawat, dan diasuransikan.

Ijarah yaitu akad pemindahan hak guna (manfaat) atas suatu barang dalam waktu tertentu

Ida Rosdiana | Prosedur Pemeliharaan Barang ...... | 70 


\section{EKSISBANK Vol. 4 No. 1 Juni 2020}

dengan pembayaran sewa (ujrah), tanpa diikuti dengan pemindahan kepemilkan barang itu sendiri (Janwari, 2015).

Berdasarkan uraian di atas yaitu suatu perjanjian, bahwa rahn atau gadai menjadikan sesuatu barang sebagai jaminan terhadap piutang, yang mungkin dijadikan pembayaran hutang tersebut. Gadai berbasis syari'ah tidak memberlakukan sistem bunga. Pegadaian syari'ah tidak mengambil keuntungan dari sistem bunga pinjaman ataupun sistem bagi hasil. Pegadaian mengambil keuntungan dari upah jasa pemeliharaan barang jaminan atau Ijarah.

Fungsi Pegadaian yaitu untuk memberikan pertolongan kepada orang yang membutuhkan dalam bentuk barang sebagai jaminan, bukan untuk mengambil keuntungan sebesar-besarnya tanpa menghiraukan kemampuan orang lain (Anggadini, n.d.; Nuzula \& Zaki, 2016). Pegadaian memberikan pinjaman kepada masyarakat dengan menahan salah satu benda sebagai jaminan dengan berdasarkan hukum gadai. Memberikan pinjaman disesuaikan dengan barang jaminan. Dari situ maka keluar berapa jumlah pinjaman dan berapa jumlah yang harus dibayar. Maka dapat diketahui berapa besar biaya pinjaman dan biaya pemeliharaan yang dibebankan kepada nasabah (Suhrawardi \& Chairuman, 1996).

Adapun dasar hukum pelaksanaan akad rahn adalah firman Allah SWT. Dalam Al-Quran surah Al-Baqarah ayat 283.

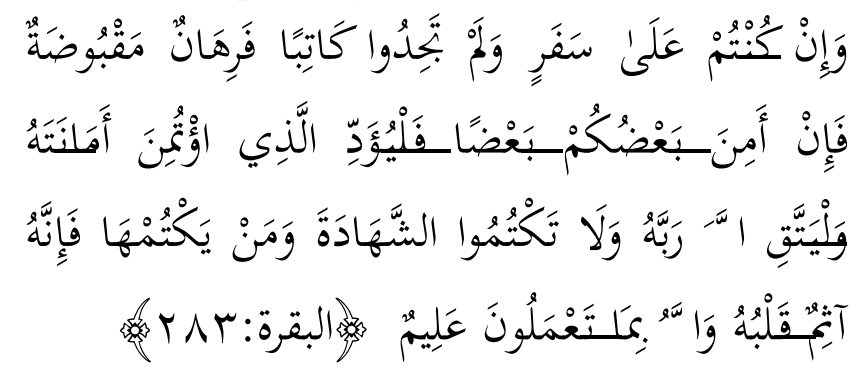

"Dan jika kamu dalam perjalanan sedang kamu tidak mendapatkan seorang penulis, maka hendaklah ada barang jaminan yang dipegang. Tetapi, jika sebagian kamu mempercayai sebagian yang lain, hendaknya yang dipercaya itu menunaikan amanatnya (hutangnya) dan hendaklah dia bertakwa kepada Allah, Tuhannya. Dan janganlah kamu menyembunyikan kesaksian karena barang siapa menyembunyikannya, sungguh, hatinya kotor (berdosa). Allah Maha mengetahui apa yang kamu kerjakan."

Ayat ini yang dijadikan sebagai dalil yang menunjukkan bahwa jaminan harus merupakan sesuatu yang dapat dipegang. Adapun fungsi gadai (marhun) pada ayat ini adalah untuk menjaga kepercayaan masing-masing pihak, sehingga penerima gadai (murtahin) meyakini bahwa pemberi gadai (rahin) beritikad baik untuk mengembalikan pinjamannya (marhun bih) dengan menggadaikan barang atau benda yang dimilikinya (marhun), secara tidak melalaikan waktu pengambilan hutangnya (Sutedi, 2011).

Selain Al-Quran juga dijelaskan dalam hadits Aisyah r.a yang diriwayatkan oleh Imam Muslim bahwa Rasulullah SAW menggadaikan baju besinya ketika sedang dalam perjalanan,

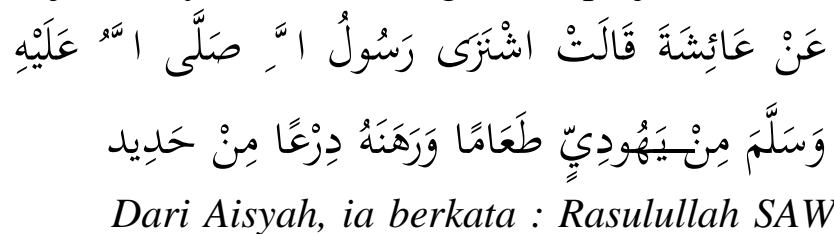
membeli makanan dari seorang yahudi dengan menggadaikan baju besinya sebagai jaminan”. (H.R Muslim).

Tujuan dari penulis melakukan penelitian ini adalah :

1. Untuk mengetahui aturan pemeliharaan barang jaminan di Kantor Pegadaian Cabang Subang.

2. Untuk mengetahui pelaksanaan pengenaan biaya pemeliharaan barang jaminan di Kantor Pegadaian Cabang Subang.

3. Untuk mengetahui tinjauan ekonomi syariah tentang biaya pemeliharaan barang jaminan di Kantor Pegadaian Cabang Subang.

\section{METODE PENELITIAN}

Metode penelitian yang penulis gunakan adalah metode deskriptif kualitatif yaitu penelitian yang menggambarkan serta menyajikan suatu peristiwa yang terjadi di lapangan dengan menggunakan teknik pengumpulan tringulasi data yaitu melalui observasi, wawancara, dokumentasi, dan juga penelitian kepustakaan dengan membaca buku, jurnal, artikel, website yang berkaitan dengan masalah yang akan diteliti (Kusuma et al., 2015; Setyawan, 2015).

Penelitian deskriptif merupakan penelitian yang berusaha mendeskripsikan sesuatu. Peneliti akan mencari tahu bagaimana pelaksanaan pemeliharaan barang jaminan yang terjadi di Pegadaian Cabang Subang dan pelaksanaan pemeliharaan barang jaminan di Pegadaian 


\section{EKSISBANK Vol. 4 No. 1 Juni 2020}

syari'ah serta mencari tahu bagaimana pandangan ekonomi syari'ah tentang pelaksanaan pemeliharaan barang jaminan. Penelitian yang penulis gunakan menurut tiga studi kasus yang dijelaskan oleh Robert K Yin yaitu penelitian eksplanasi. Karena penelitian eksplanasi dimaksudkan agar peneliti lebih mengetahui dan mengembangkan konsep sesuai dengan keadaan di lapangan.

Penelitian ini tidak harus dilakukan oleh orang yang sudah mahir dalam masalah yang diteliti tersebut. Orang atau masyarakat sering tidak puas hanya sekedar mengetahui apa yang terjadi, bagaimana terjadinya, tetapi juga ingin tahu mengapa hal tersebut bisa terjadi. Oleh sebab itu penulis bertujuan untuk mengkonfirmasi sebab terjadinya suatu masalah (Wijaya, 2018).

Data primer merupakan data yang diperoleh secara langsung oleh penulis dari responden terpilih pada lokasi penelitian. Data primer diperoleh dengan cara wawancara. Pada tanggal 19 juni 2019 penulis mendatangi kantor Pegadaian Cabang Subang, berbagai pertanyaan yang penulis tanyakan seperti struktur organisasi, bagaimana cara menentukan nilai taksiran, biaya pemeliharaan, barang apa saja yang bisa dijadikan sebagai jaminan, produk apa saja yang tersedia di pegadaian Cabang Subang.

Mengenai pemeliharaan barang jaminan penulis mencari tahu kepada Narasumber yaitu Bapak Yudha dan Pak Reza beliau merupakan Pegawai di Kantor Pegadaian Cabang Subang. Pak Yudha merupakan bagian makro atau lapangan di Pegadaian Cabang Subang sementara Pak Reza bagian penaksir di Kantor Pegadaian Cabang Subang.

Dengan begitu beliau mampu menjawab pertanyaan yang akan penulis sampaikan atas dasar pengalaman yang beliau dapatkan. Adapun data sekunder merupakan data yang diperoleh dari jurnal, skripsi, situs internet, serta bacaan lain yang berhubungan dengan penelitian yang digunakan sebagai data penunjang untuk mengetahui bagaimana gadai (Rahn) serta timbulnya biaya pemeliharaan barang jaminan atau ijarah.

Adapun teknik pengumpulan data yaitu yang pertama observasi yaitu dengan melakukan pengamatan langsung terhadap objek yang diteliti, dalam hal ini penulis sendiri mencoba menjadi nasabah Pegadaian Cabang Subang. Kemudian wawancara merupakan pertemuan dua orang untuk bertukar informasi melalui tanya jawab dengan Mengajukan pertanyaan yaitu pengumpulan data yang dilakukan dengan cara memberikan daftar pertanyaan kepada Pegadaian Cabang Subang dan tokoh masyarakat yang mengetahui dan faham mengenai praktik pemeliharaan barang jaminan.

Setelah mendapatkan data kemudian menggunakan tringulasi data yaitu tenik pemeriksaan keabsahan data dengan mencari tahu sesuatu hal yang lain diluar data yang ada untuk keperluan pengecekan atau sebagai pembanding. Teknik tringulasi ini digunakan sebagai pemeriksaan melalui sumber lain. Dalam pelaksanaanya penulis melakukan wawancara dengan pengelola Pegadaian Cabang Subang, tokoh ulama, dan MUI Kabupaten Subang. Kemudian hasil wawancara tersebut penulis melakukan pengamatan untuk mengetahui perhitungan pemeliharaan barang jaminan. Dengan dilengkapi penelitian yang dilakukan dengan cara pengumpulan data, melalui bahanbahan kepustakaan berupa tulisan-tulisan ilmiah, jurnal, laporan penelitian, buku-buku, dan sumber lain seperti internet dan surat kabar yang berhubungan dengan topik yang diteliti.

Kemudian penulis melakukan analisis data merupakan upaya untuk mencari secara sistematis hasil observasi, wawancara untuk meningkatkan pemahaman penelitian tentang kasus yang diteliti.

\section{HASIL DAN PEMBAHSAN}

Aturan pemeliharaan barang jaminan atau perlindungan hukum dalam peraturan pemerintah maupun dalam fatwa untuk melaksanakan transaksi gadai di Pegadaian konvensional maupun Pegadaian syari'ah tentunya memiliki teknis pelaksanaan tersendiri walaupun kurang lebih hampir sama.

Berdasarkan wawancara dengan Ust.Mumuh Muhidin salah satu tokoh ulama Dusun Ciherang Desa Gunung Tua Kecamatan Cijambe Kabupaten Subang yaitu tepatnya sekitar tempat tinggal penulis pada hari selasa 17 September 2019 bahwa. Mengenai bagaimana aturan pemeliharaan barang jaminan tidak ada atau tidak terdapat dengan jelas dan terperinci didalam Al-Qur'an maupun Hadits. Hal tersebut ada karena hasil dari ijtihad para ulama dengan mencari dasar hukum dari Al-Quran dan Hadits untuk memecahkan kasus tersebut.

Yaitu mengenai bagaimana aturan pemeliharaan barang jaminan. Dari sinilah para 
ulama dapat menjawab kasus-kasus baru seiring dengan berkembangnya zaman.

Masih menurut Ust. Mumuh Muhidin Dasar hukum yang digunakan para ulama mengenai gadai ini yakni bersumber pada Q.S Al-Baqarah ayat 283.

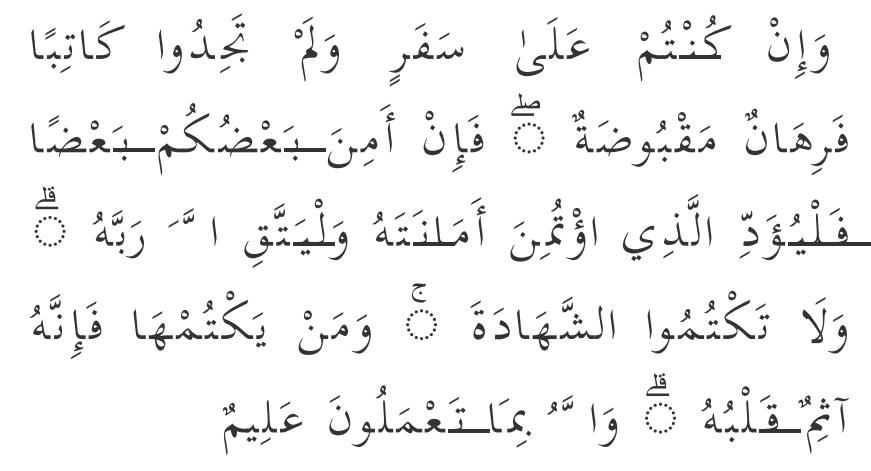

"Jika kamu dalam perjalanan (dan bermu'amalah tidak secara tunai) sedang kamu tidak memperoleh seorang penulis, maka hendaklah ada barang tanggungan yang dipegang (oleh yang berpiutang). Akan tetapi jika sebagian kamu mempercayai sebagian yang lain, maka hendaklah yang dipercayai itu menunaikan amanatnya (hutangnya) dan hendaklah ia bertakwa kepada Allah Tuhannya; dan janganlah kamu (para saksi) menyembunyikan persaksian. Dan barangsiapa yang menyembunyikannya, maka sesungguhnya ia adalah orang yang berdosa hatinya; dan Allah Maha Mengetahui apa yang kamu kerjakan."

Berdasarkan landasan tersebut secara garis besarnya ulama bersepakat bahwa rahn (gadai) merupakan transaksi yang diperbolehkan dan menurut sebagian besar (jumhur) ulama ada beberapa rukun bagi akad rahn terdiri dari arrahn, marhun, murtahin, sesuatu yang karenanya diadakan gadai, yakni harga, dan sifat akad rahn.

Adapun menurut MUI kabupaten Subang dengan penulis mendatangi kantor MUI kabupaten subang berada di Jl. Bagus Yabin Kelurahan Cigadung Kecamatan Subang Kabupaten Subang dengan Bapak Husen selaku bendahara MUI kabupaten Subang mengenai rahn (gadai) dalam hal ini tidak bisa dipisahkan dengan akad ijarah. Dalam penerapannya atau implementasinya akad ini nasabah memberikan fee atau biaya sebagai imbalan untuk layanan yang sudah dilakukan kepada pihak Pegadaian ketika masa kontrak telah berakhir.

Mengenai gadai terdapat dalam fatwa DSN No.25/DSN-MUI/III/2002 tentang gadai sementara ijarah dalam DSN NO: 09/DSN-
MUI/IV/2000 tentang pembiayaan ijarah. Sementara tentang besarnya pemeliharaan barang jaminan terdapat dalam fatwa DSN MUI Nomor 68/DSN-MUI/III/2008 disebutkan bahwa besaran biaya pemeliharaan dan penyimpanan didasarkan pada pengeluaran riil dan beban lainnya berdasarkan akad ijarah. Dalam akad ijarah ini Pegadaian berhak menarik biaya sewa atas penyimpanan barang jaminan milik nasabah.

Menurut Pa Reza Azhari, SE selaku penaksir di Pegadaian Cabang Subang bahwa pemeliharaan barang jaminan yaitu dengan menetapkan nilai taksiran lalu menganalisa kadar emas atau kelayakan barang jaminan dengan berdasarkan harga pasar yang berlaku.

Sebuah perusahaan apabila tidak memperoleh pendapatan dalam kegiatannya maka proses berlangsungnya kegiatan perusahaan tersebut akan terhambat atau bahkan akan terhenti. Pegadaian akan dirugikan karena dalam operasionalnya tidak mendapatkan pemasukan atau keuntungan dalam menunjang kegiatannya.

Pegadaian memperoleh keuntungan dari biaya penyimpanan barang jaminan atau biaya yang dipungut dari biaya pemeliharaan barang jaminan. Pegadaian melakukan pemungutan biaya pemeliharaan dan penyimpanan barang dengan mengenakan persentase tambahan pembayaran kepada pemilik barang jaminan. Biaya tambahan yang dikenakan berupa administrasi, asuransi, dan penyimpanan atau perawatan barang jaminan.

Mengenai praktik gadai di Pegadaian Cabang Subang adanya pelakasanaan pemeliharaan barang jaminan, berdasarkan apa yang penulis lihat biaya pemeliharaan tersebut yaitu untuk biaya penyimpanan, bukan untuk biaya perawatan. Padahal penyimpanan barang gadai oleh Pegadaian itu memang sudah menjadi kewajiban yang muncul dari akad gadai. Kewajiban penyimpanan barang gadai tersebut secara otomatis sudah ada. Namun pada saat penentuan biaya pemeliharaan dan penyimpanan barang jaminan menimbulkan pertanyaan. Karena besarnya biaya pemeliharaan tersebut tergantung jenis barang seperti apa yang digadaikan dan beban biaya yang seiring dengan bertambahnya waktu masa pinjaman semakin bertambah pula biaya pemeliharaannya.

Maka dari itu dalam menggadai haruslah dalam keadaan yang benar-benar mendesak dan penting. Sebab ada hal-hal yang harus diperhitungkan. Namun disamping itu apabila

Ida Rosdiana | Prosedur Pemeliharaan Barang ...... 73 


\section{EKSISBANK Vol. 4 No. 1 Juni 2020}

Pegadaian tidak mendapatkan pemasukan dalam menunjang kegiatannya maka kegiatan Pegadaian tersebut tidak akan terus berjalan. Maka dari itu proses penyimpanan ini timbul biaya-biaya yang meliputi pemeliharaan atau biaya perawatan, dan keseluruhan proses kegiatan.

Pada prinsipnya transaksi gadai di Pegadaian Cabang Subang beberapa hal sudah sesuai dengan peraturan OJK maupun fatwa dan ada pula yang belum diketahui bagaimana aturannya, yaitu mengenai maksimal biaya pemeliharaan. Namun intinya Pegadaian Cabang Subang berhak mengambil biaya pemeliharaan atau beban biaya atas upah layanan jasa yang telah dilakukan kepada nasabah sesuai dengan jumlah yang disepakati oleh kedua belah pihak. Yaitu terdapat dalam Fatwa DSN MUI No.68/DSN-MUI/III/2018 tentang rahn tasjily dan undang-undang No.10 Tahun 1998 tentang perubahan atas UU Nomor 7 Tahun 1992.

\section{PENUTUP \\ Kesimpulan}

Pelaksanaan pemeliharaan barang jaminan di Pegadaian Cabang Subang yaitu biaya yang dibebankan kepada nasabah tergantung pada nilai taksiran barang jaminan dan lamanya masa pinjaman. Mengenai prakteknya bahwa biaya tersebut adalah biaya yang dikeluarkan oleh nasabah untuk biaya penyimpanan.

Sesuai dengan fatwa DSN MUI No.68/DSN-MUI/III/2018 tentang rahn tasjily bahwa biaya penyimpanan dan pemeliharaan dikeluarkan berdasarkan pengeluaran riil dan beban lainnya berdasarkan akad ijarah. Dengan kata lain bahwa nasabah memberikan upah (ijarah) kepada Pegadaian agar barang jaminan miliknya dijaga dan dirawat.

Menurut ekonomi syari'ah bahwa penyimpanan barang gadai menjadi kewajiban murtahin. Kewajiban tersebut secara otomatis dilakukan oleh murtahin. Namun tujuan ekonomi syariah yaitu untuk mencapai fallah di dunia dan di akhirat. Prinsip syariah ini bertujuan untuk menciptakan masyarakat yang seimbang.

Barang jaminan sama halnya dengan amanat. Pegadaian akan memberikan ganti rugi jika barang jaminan milik nasabah rusak. Maka dari itu Pegadaian akan berusaha semaksimal mungkin agar barang jaminan milik nasabah tidak rusak. Dalam menunjang kegiatan tersebut Pegadaian mengenakan biaya penyimpanan dan pemeliharaan. Dengan begitu hadirnya Pegadaian diharapkan mampu menekan munculnya peminjaman yang cenderung merugikan masyarakat yang sedang membutuhkan. Akan tetapi penulis tidak menemukan Fatwa atau dasar hukum mengenai maksimal biaya pemeliharaan dan penyimpanan atau berapa biaya yang harus ditanggung oleh rahin/nasabah.

\section{DAFTAR PUSTAKA}

Anggadini, S. R. I. D. (n.d.). Penerapan Teori Dan Aplikasi Penggadaian Syariah Pada Perum Penggadaian Di Indonesia. 15(1), 3 12.

Bukido, R., \& Hasan, F. (2016). Penerapan Akad Ijarahpada Produk Rahndi Cabang Pegadaian Syariah Istiqlal Manado. Jurnal Ilmiah Al-Syir'ah, 14(1).

Hafidah, N. (2013). Kajian Prinsip Hukum Jaminan Syariah Dalam Kerangka Sistem Hukum Syariah. Rechtidee, 8(2), 198-215. https://doi.org/10.21107/ri.v8i2.696

Haikal, M. (2018). Hukum Pemanfaatan tanoh gala Menurut Fikih Syafiiyah. Jurnal Al Mabhats, 3(2), 261-281. https://ejurnal.iainlhokseumawe.ac.id/index. php/al-mabhats/article/view/240

Ichsan, N. (2016). Akad Bank Syariah. AsySyir'ah: Jurnal Ilmu Syari'ah Dan Hukum, 50(2), 399-423. https://doi.org/10.14421/ASY-

SYIR'AH.2016.502-05

Janwari, Y. (2015). Fikih Lembaga Keuangan Syari'ah. Rosda Karya.

Kusuma, N. A., Irhandayaningsih, A., \& Kurniawan, A. T. (2015). Analisis Penggunaan Metode Mind Mapping Untuk Meningkatkan Kemampuan Membaca Pemahaman (Studi Kualitatif Siswa Tunarungu SD Kelas V di SLB Negeri Semarang). Jurnal Ilmu Perpustakaan, 4(2), 29-38.

https://ejournal3.undip.ac.id/index.php/jip/a rticle/view/9501

Maemunah, M. (1970). Analisis Perlakuan Akuntansi Gadai Emas Syariah Pada Bank Bjb Syariah Kantor Cabang Pembantu Karawang. Jurnal Buana Akuntansi, 1(1). https://doi.org/10.36805/akuntansi.v1i1.88

Ida Rosdiana | Prosedur Pemeliharaan Barang ...... | 74 
EKSISBANK Vol. 4 No. 1 Juni 2020

Nuzula, K. F., \& Zaki, I. (2016). Tinjauan Implementasi Fatwa DSN NO.25/DSNMUI/III/2002 Pada Pelaksanaan Penjualan Barang Gadai Yang Tidak Ditebus Di Bank JATIM Syariah. Jurnal Ekonomi Syariah Teori Dan Terapan, 3(5), 418. https://doi.org/10.20473/VOL3ISS20165PP 418

Setyawan, W. (2015). Eksistensi Kurikulum Pesantren Muamalah Adalah Di Era Global. LISAN AL-HAL: Jurnal Pengembangan Pemikiran Dan Kebudayaan, 9(2), 397-406. https://doi.org/10.35316/10.1234/vol3iss2p p230

Suhrawardi, \& Chairuman. (1996). Hukum Perjanjian Dalam Islam. Sinar Grafika.

Sutedi, A. (2011). Hukum Gadai Syariah. Alfabeta.

Wijaya, H. (2018). Analisis Data Kualitatif Ilmu Pendidikan Teologi. Sekolah Tinggi Theologia Jaffray. 